\title{
On the Threshold of Scientific Medicine: Gerard van Swieten and His Perception of the Pathophysiology in Traumatic Brain Injury
}

\author{
Olaf E.M.G. Schijns ${ }^{a, b, c}$ Peter J. Koehler ${ }^{d}$ \\ ${ }^{a}$ Department of Neurosurgery, Maastricht University Medical Centre (MUMC+), Maastricht, The Netherlands; \\ ${ }^{b}$ Academic Centre for Epileptology, Maastricht University Medical Center (MUMC+) and Kempenhaeghe, Maastricht \\ - Heeze, The Netherlands; 'School for Mental Health and Neuroscience (MHeNS), University Maastricht (UM), \\ Maastricht, The Netherlands; ${ }^{\mathrm{d}}$ Neurologist, Faculty of Health, Medicine and Life Sciences, University Maastricht, \\ Maastricht, The Netherlands
}

\section{Keywords}

Gerard van Swieten · Traumatic brain injury

\begin{abstract}
Gerard van Swieten (1700-1772), famous pupil of Professor Herman Boerhaave (1668-1738) of Leiden University and personal physician of Austrian Habsburg Empress Maria Theresa (1717-1780). Herman Boerhaave was a renowned Dutch physician inside and outside Europe in the 18th century. He was not only appointed professor in medicine, chemistry, and botany but also a chancellor of the Leiden University in 1714 and published his well-known Aphorismi de cognoscendis et curandis morbis in 1709. Gerard van Swieten commented upon Boerhaave's aphorisms and demonstrated actual knowledge, less well-known among the medical community, about the pathophysiology of traumatic brain injury which half a century later (19th century) became known as the Monro-Kellie doctrine. Using the original commentaries upon Boerhaave's aphorisms by van Swieten himself, we explored his way of formulating the pathophysiological concept of traumatic brain injury, which still is valid today.
\end{abstract}

(c) 2021 The Author(s)

Published by S. Karger AG, Basel

\section{Introduction}

Gerard van Swieten (1700-1772) (Fig. 1) was one of the 2 most eminent pupils of Herman Boerhaave, a renowned physician in the early 18th century (1668-1738), the other being the Swiss physician Albrecht von Haller (1708-1777). Born as the son of a notary in an established Roman Catholic family in Leiden, van Swieten became an orphan at age 12 years. With a small part of his father's heritage, he started to study state sciences and philosophy in Leuven, Southern Netherlands, in 1716, switching to medicine in Leiden in 1718. Roughly, his life can be divided into 2 periods: the Leiden (1700-1745) and the Vienna period (1745-1772). He concluded the study of medicine with a doctoral thesis in 1725 , after which he worked as a physician and pharmacist up to 1745 . During that period, he continued to attend the academic lectures of Boerhaave, and because of his mastery in tachygraphy, he succeeded to write down, word by word, all lecture notes.

Boerhaave, whom von Haller mentioned Communis Europae Praeceptor, experienced many problems with forged publications under his name, in which wrong views had been presented, and he warned the public of this, for in- karger@karger.com www.karger.com/ene

Karger $\stackrel{\text { ' }}{=}$

BOPEN ACCESS
(C) 2021 The Author(s)

Published by S. Karger AG, Basel

This is an Open Access article licensed under the Creative Commons Attribution-NonCommercial-4.0 International License (CC BY-NC) (http://www.karger.com/Services/OpenAccessLicense), applicable to the online version of the article only. Usage and distribution for commercial purposes requires written permission.
Correspondence to:

Olaf E.M.G. Schijns, o.schijns@mumc.nl 


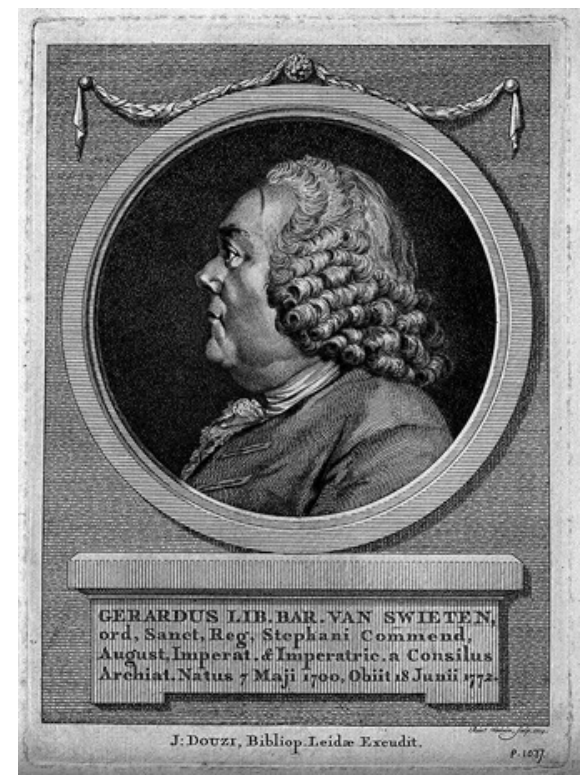

Fig. 1. Gerard van Swieten, line engraving by R. Vinkeles 1773 (made posthumously) Courtesy Wellcome Collection.

stance, in a newspaper message in the Leydse Courant of 9 October 1726. Two years later, the Dutch government forbade copying the work of Leiden professors [1]. Therefore, after Boerhaave's death, both pupils were hesitant in complying with requests of publishers to publish commentaries of his work. von Haller as well as van Swieten published extensively annotated commentaries in the title of which Boerhaave's name was clearly indicated. von Haller commented upon Boerhaave's Institutiones medicae of 1708 (Hermanni Boerhaave Praelectiones academicae in proprias institutiones rei medicae), making clear distinction between his master's and his own work. van Swieten commented upon Boerhaave's 1495 Aphorismi de cognoscendis et curandis morbis (1709; translated by J. Delacoste and published as Aphorisms: concerning the knowledge and cure of diseases in 1715) and compiled a 5-volume Commentaria in Hermanni Boerhaave aphorismos de cognoscendis et curandis morbis in the period between 1742 (1st volume) and 1772 (5th volume). It was translated into English and published in 18 volumes as Commentaries upon Boerhaave's Aphorisms Concerning the Knowledge and Care of Diseases between 1759 and 1773 (Fig. 2) [2]. He became a worthy successor to his master as a prominent physician of well-known patients. However, after the death of Boerhaave in 1738, he could not be appointed as his academic successor at the University of Leiden because of his Roman Catholic faith. At the time, the Northern Netherlands was predominantly Protestant.

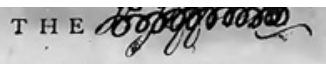

C O M M E N T A R I E S

\begin{tabular}{llllll}
\hline & P & T H B
\end{tabular}

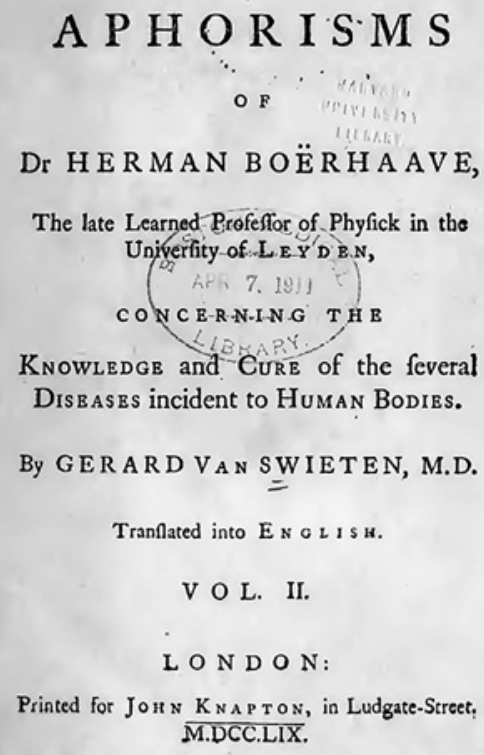

Fig. 2. Title page of the English translations of van Swieten's Commentaries.

In 1743, the Austrian ambassador in the Netherlands delivered a letter to van Swieten from the 26-year-old Austrian Habsburg Empress Maria Theresa (1717-1780), with the request, to serve the court as her personal physician and university professor in Vienna as the imperial court physician had recently died [3]. In 1745, van Swieten, at 45 years of age, decided to accept this imperial invitation and left Leiden permanently to continue his career in Vienna. Once in Vienna, he was directly appointed as chief physician of the court and director of the court library, leading to his role as the reformer of the university. In this Austrian period, he was given the assignment to drastically reform not only the university but also the health-care system and to improve medical education for students with the methods learned from Boerhaave [3]. This resulted in the creation of a "Leiden medical school" in Vienna, which started to rival the wellknown, established older European universities. Especially this academic reform brought European renown for van Swieten. For nearly 30 years, in this Viennese period, he continued editing his medical encyclope- 
dia mentioned previously, which, in the second half of the 18th century, served as the "Bible of medicine" or Thesaurus medicinae Boerhaavianae, a kind of "state-of-the-art" medical work of the 17th and the early 18th century.

Remarkably, little has been written about the scientific work of van Swieten, including his 5-volume Commentaria. The content of these Commentaria consists mainly of historical citations of ancient physicians like Hippocrates (460-370 BCE) and Galenus (129-199), completed with those of Boerhaave, to which van Swieten added recent knowledge from scientific journals, including Journal des Sçavans, the Philosophical Transactions of the Royal Society of London, and the Mémoires de l'Académie de Sciences, supplemented by his own critical observations on his patients [1]. Comparable to other medical books in those days, neurological topics, including epilepsy, stroke, vertigo, headache, and traumatic brain injury, were also commented upon in the Commentaria. About some topics, for instance, tremor and cluster headache (in a chapter on febris intermittens), historical reviews have been published. In the present article, we wish to discuss van Swieten's ideas on the pathophysiology of traumatic brain injury, as an example of 18th-century understanding of the subject. More in particular, we shall discuss his perception of the role of the cerebellum and intracranial pressure ratios.

\section{Of Wounds in the Head}

The chapter "Of wounds in the head" in volume 2 of the English edition of the Commentaries upon Boerhaave's Aphorisms Concerning the Knowledge and Care of Diseases comprises over 200 pages [2]. With respect to the condition nowadays described as coma, following traumatic brain injury (section 275), van Swieten, as in all other commented aphorisms, first repeated a part of Boerhaave's aphorism (no. 275), mentioning "depravation, diminution, or a total loss of the sight, hearing, smelling, tasting, or feeling," and adding that there could be a "deep sleep, and a difficult or noisy respiration," sometimes accompanied by "fever, a flux of blood from the nose, mouth, or ears, with a redness of the face and eyes" (van Swieten, 1759, pp. 453-4) [2]. On severe coma (using the term apoplexy) preceding death van Swieten commented:

Apoplexies, fevers, and death. The symptoms or appearances which we have hitherto enumerated, denote that the actions of the brain are disturbed only by a slight compressure [sic], or indentation of the skull; but when this compressure has been so far increased, as to abolish all the external and internal senses, with the voluntary motions, there is then the appearance of a profound or dead sleep, called an apoplexy; which is almost constantly attended with a strong and quick pulse, from the action of the cerebellum still remaining, or even being increased because it lies better secured from the compressure by the processes of the dura mater; but when at length the cerebellum is also compressed, or its structure destroyed by the increased motion of the blood (for when the brain is compressed, and the blood denied a free passage through the encephalon, its force is almost entirely spent on the cerebellum), then death follows (van Swieten, 1759, p. 428) [2].

For a better understanding of his views of the relation between the cerebrum and cerebellum in traumatic brain injury, the following passage is worth mentioning:

But as the cerebellum is more firm in its [sic] substance, and more securely lodged than the brain itself; hence it almost constantly happens that a depression of the skull first injures the actions of the brain, and afterwards invades the actions of the cerebellum, on which life more immediately depends (van Swieten, 1759, p. 419) [2].

In fact, he was explaining his observations, applying the contemporary pathophysiologic knowledge, how cerebral functions stop first and autonomic functions only late in the process of deterioration. He was aware however that not only depressed fractures caused these phenomena:

For, as we have several times observed before, the whole cavity of the skull is always most exactly filled; so that extravasated humours cannot be there collected, without pressing upon the contained encephalon; whence all those maladies are to be feared, which may arise from this compression, and which we enumerated in $\$ 267$. For it matters not in this case what the compressing cause be, whether an alteration in the figure of the skull, so as to lessen its cavity, or an extravasation of the humours, the capacity of the skull remaining the same, so that the humours take up the space which the brain itself before occupied, and with which the skull was before most exactly filled; for the effect will be always the same, namely, a disturbance or abolition of the functions of the brain, from a compressure of its substance (van Swieten, 1759, p. 445) (Fig. 3) [2].

Two aspects from these quotations may be of interest to the present reader. The first is his attribution of the action of the cerebellum responsible for "a strong and quick pulse" and its function breaking down only late in the process of deterioration, thinking the organ is better protected from external impact. The second is van Swieten's mentioning the capacity of the skull remaining the same "so that the humors take up the space which the brain itself before occupied," which already is a precursor on the later published Monro-Kellie doctrine. 
For, as we have feveral times obferved before, the whole cavity of the fkull is always moft exactly filled; fo that extravafited humours cannot be there collected, without prefling upon the contained encephalon; whence all thote maladies are to be feared, which may arife from this compreftion, and which we enumerated in $\$ 267$. For it matters not in this cafe what the comprcfing caufe be, whether an alteration in the figure of the fkull, fo as to leffen it's cavity, or an exiravafation of the humours, the capacity of the fkull remaining the fame, fo that the humours take up the fpace which the brain itfelf before óccupied, and with which the fkull was before moft cxaclly filled; for the effect will be always the fame, namcly, a difturbance or abolition of the functions of the brain, from a compreffure of it's fubftance.

Fig. 3. Section from van Swieten's Commentaries on Boerhaave's aphorism no. 273 (van Swieten, 1759, p. 445).

\section{Vital Functions in the Cerebellum or Medulla Oblongata?}

Through the ages, various functions have been attributed to the cerebellum, including a motor function in the Galenic period, a memory function in the medieval period (within the concept of ventricular localization; the "third cell," our present fourth ventricle, was situated below the cerebellum) and vital functions. With respect to the latter, Thomas Willis (1621-1675) believed that the animal spirits that are conducted through the vagus nerves have their origin in the cerebellum and run through the medulla oblongata to the lungs and heart, where they exert these vital functions. The pertinent text can be found in his well-known book Cerebri Anatomy, notably in chapter 16 ("De spirituum in Cerebello productorum, propter functionis involuntariae actus varia diataxi, and Exercitio diversimodo"; Willis, 1664, p. 196) [4]. It was well-known that injury to the hindbrain could affect these functions, and coarse experimental work during the 17th century seemed to confirm this as removal of the cerebellum resulted in the arrest of respiration and heartbeat. This belief continued despite the experimental finding that the heart continues beating after its removal from the thorax. Moreover, the Swiss physician Johann Jacob Wepfer (1620-1695) had found in experiments that following decapitation, the heart beating went on for several hours. However, several other 17 th-century researchers reported the fatal effect of removal of the cerebellum (Neuburger, 1897, pp. 1-39) [5].
Even during this early period of crude experimentation, some were able to keep animals alive for some time following removal of the cerebellum. French physician Pierre Chirac (1650-1732) combined the experiment with artificial respiration, in casu inflation of air. These physicians gradually began to realize that previous work had been carried out inaccurately. François Pourfour du Petit (1664-1741) and Antonio Valsalva (1666-1723) observed survival for some time after removal of the cerebellum. Abraham Kaau-Boerhaave (1715-1758; one of Herman Boerhaave's nephews, who moved to St. Petersburg) was one of the physicians, who established the vital role of the medulla oblongata, following all experiments, in which he injured the brain, the cerebellum ("a pen or knife was thrust inside the cerebellum, the cardiac and respiratory function do not stop immediately"), or the medulla oblongata. Others, among whom Anne-Charles Lorry (1726-1783) and Justus Arnemann (1763-1806), were aware of the technical shortcomings of many of the early experiments on the cerebellum that resulted in massive bleeding in the infratentorial compartment and endeavored to prevent this; von Haller considered the heart almost completely independent. "For certain experiments, even of our own making, show that it [the cerebellum] has borne wounds and scirrhi, without taking away life;... not very rarely, wounds of the cerebellum cure" (Haller, 1786, p. 217) [6]. His followers denied localization of functions in the brain, including the cerebellum. It is evident that van Swieten, when writing about the autonomic functions and the cerebellum, was still adhering to the old ideas of Willis, when he wrote the text quoted before.

\section{Capacity of the Skull and Pressure Ratios}

With respect to the second issue, "the capacity of the skull" and "the humours[that] take up the space which the brain itself before occupied," it would be of interest to know, whether there has been any relation between van Swieten, who wrote this text, and Alexander Monro secundus (1733-1817) and more, in particular George Kellie (1770-1829), who later postulated what is now known as the Monro-Kellie doctrine. From the previous paragraphs, it can clearly be deduced that although Boerhaave was aware of the effects of compression of the brain (aphorism no. 267, van Swieten, 1759, p. 417) [2], van Swieten must have been acquainted with the relation between pressure and volume within the rigid box of the neurocranium and the deleterious effects of a dysbalance be- 
tween these 2 parameters on the neurological condition of the patient, in case of trauma or other space occupying disease. Commenting upon aphorism no. 267 (on compression of the brain by fractures; van Swieten, 1759, p. 417) [2], van Swieten, apparently aware of the ancient Greek geometric views on the circle, nowadays known as the compactness measure of shape, noted:

It appears from geometry, that a circle has the greatest area of all figures, having equal sides; but the shape of the skull approaches that of a sphere, and therefore when the cranium is depressed, it's [sic] capacity will be diminished. It is also known from physiology, that the cavity of the skull is always exquisitely full in the state of health; insomuch that after cutting out a piece of the cranium, the contained encephalon immediately protuberates, so that the piece of bone cannot be placed in its [sic] former situation unless forced. It is therefore evident, that when the figure of the skull is changed by a depression, its [sic] contents must consequently be compressed (van Swieten, 1759, p. 418) [2].

When reading this, one could argue that Monro or Kellie had knowledge about van Swieten's theory. The modern medical community uses the eponym of the Monro-Kellie doctrine to describe the pathophysiological consequences of raised intracranial pressure within the rigid box of the skull. This doctrine is named for 2 Scottish physicians Alexander Monro secundus, professor of anatomy at the University of Edinburgh and surgeon, and later physician George Kellie, pupil and later collaborator of Monro. These 2 physicians worked in the time period of the Enlightenment, with its characteristic features of observing, experimenting, doubting about existing theories, and writing down new theories even as consulting other medical doctors. Kellie became well-known by his description of 2 postmortem cases in 1824. Three years previously, "Mr. Cheyne and I were requested by the Magistrates to inspect" the bodies and give an opinion of the cause of death. They found that "the veins in the meninges and surface of the brain are congested and the associated arteries are relatively bloodless, while the brain is otherwise normal"... and then formulated that...."when the cavity of the cranium is encroached upon by depression of its walls, compensation may be made at the expense of circulatory fluid within the head; less blood is admitted and circulated..." [7]. He also admitted that 2 colleagues, Alexander Monro secundus and John Abercrombie (1780-1844), needed to receive the credits of formulating this medical doctrine.

Indeed, Monro, in the chapter "Of the circulation of the blood in the head" of his Observations on structure and functions of the nervous system wrote that "the substance of the brain, like that of the other solids of our body, is nearly incompressible, the quantity of blood within the head must be the same, or very nearly the same, at all times, whether in health or disease, in life or after death, those cases only excepted, in which water or other matter is effused or secreted from the blood-vessels" (Monro, 1783, p. 5) [8]. This is a section to which Kellie referred in his 1824 report (Kellie, 1824, p. 102) [7]. When explaining his theories on this subject, Monro referred to Boerhaave and Haller (Monro, 1783, p. 3) [8]. In fact, Monro's father (Monro primus, 1697-1767) had been Boerhaave's student in Leiden and Monro secundus himself had studied in Edinburgh, London, Berlin, and Leiden. It may be of interest to note that after Boerhaave's death, Leiden's popularity for European medical students gradually declined in favor of Edinburgh. Kellie was aware of the work of van Swieten, but he did not refer to him with respect to the pressure ratios. However, he did refer to his Commentaria within the same article, when discussing the effects of ligature of carotid arteries and jugular veins, arguing that dogs have quite large anastomoses to bypass the effects of ligature (Kellie, 1824, p. 164-5) [7]. van Swieten did not notice any abnormal behavior in the dog, and upon autopsy, "no disturbance appeared in the brain, but its [sic] bulk seemed rather increased than diminished" (van Swieten, 1759, p. 97) [2]. Reading the previous paragraph, one could interpret that van Swieten already, at least partly, preformulated the content of the doctrine, which in the 19th century became the eponym named after his colleagues Monro secundus and Kellie.

\section{Trepanation}

Some of the aphorisms and commentaries discuss trepanation, in particular in cases of depressed skull fractures or if "some fragment of it injures the encephalon" (van Swieten, 1759, p. 482) [2]. In other cases, in which signs indicate brain injuries without evident fractures, "extravasated humors" could be the cause. In such cases, van Swieten advised "to wait a few hours" and apply conservative measures ("plentiful evacuations" of fluids) as patients "with signs which denote that the functions of the encephalon are much injured after wounds of the head" (van Swieten, 1759, p. 482) [2], may revive after some hours. Only if it lasted longer, for instance, 12 hours

and all the symptoms rather increase, there then remains but one other method of relief, namely, by procuring a discharge to the extravasated humours, by perforating the skull with a trepan. In such cases, the patient's friends are to be acquainted that 
certain death is at hand, but there still remains this one doubtful and difficult operation... a certain cure ought never to be promised (van Swieten, 1759, p. 482) [2].

It is clear that in his Commentaries, van Swieten was cautious about trepanation. Furthermore, although making the right observations of the signs, he explained these in the old way, following Willis, where it concerns the function of the cerebellum. With respect to the pressure ratios, he sensed what is taking place within the skull in patients with traumatic brain injury. With this knowledge, in the mid-18th century, Monro and, more in particular Kellie, elaborated the intracranial pressure-volume relationship upon Monro's insights [8,9].

Knowledge on the function of the cerebellum increased in the early 19th century with the experiments by Luigi Rolando (1773-1831), and in particular Pierre Flourens (1794-1867), who, in their animal experiments, applied a much better operation technique with full exposure and visual control [10]. Knowledge of intracranial pressure ratios also improved as Monro and Kellie did not yet refer to the cerebrospinal fluid as the third parameter within the rigid skull, the presence of which was demonstrated for the first time by François Magendie (1783$1855)$ in 1842. The famous Theodor Kocher (1841-1917), professor of surgery in Berne, Switzerland, had a serious scientific interest in the pathophysiology of the intracranial circulation and stimulated Harvey Cushing (18691939) to do cerebrovascular research in his laboratory. In this period, Cushing described the coupling of arterial hypertension and bradycardia in raised intracranial pressure, nowadays known as the Cushing reflex [11]. In later years, Cushing extended this laboratory observation and applied it to human pathophysiology. Kocher was subsequently the first to describe the procedure of the decompressive craniectomy to rapidly decrease high intracra- nial pressure, which nowadays is a standard surgical technique for the treatment of many patients with traumatic brain injury, when conservative treatment options fail. Some years later, coming to the conclusion that raised intracranial pressure is a general problem in the rigid skull, instead of a problem in a part of the brain, Cushing concluded that the Monro-Kellie doctrine had clinical relevance and expressed it in a formula (1901), which is still actual in the treatment of patients with raised intracranial pressure (cerebral perfusion pressure $=$ mean arterial pressure - intracranial pressure).

To conclude, Gerard van Swieten and Boerhaave (late 17 th-early 18 th century), in a more restricted form, already had adequate pathophysiological theories about the mechanism by which raised intracranial pressure could provoke serious neurological deterioration due to compression on supra- and subsequently infratentorial structures, which in the 19th and the early 20th century became established knowledge.

\section{Conflict of Interest Statement}

The authors report no conflict of interest.

\section{Funding Sources}

There are no funding sources for this study.

\section{Author Contributions}

O.S.: manuscript concept/draft/review. P.K.: manuscript concept/draft/review.

\section{References}

1 Lesky E. Albrecht von Haller, Gerard van Swieten und Boerhaavens Erbe. Ges. 1958;15(34):120-40.

2 Van Swieten G. Commentaries upon Boerhaave's aphorisms concerning the knowledge and care of diseases. London: Knapton; 1759. Vol. 2.

3 Kidd M, Modlin IM. Van Swieten and the renaissance of the Vienna Medical School. World J Surg. 2001;25:444-50.

4 Willis T. Cerebri anatome cui accessit nervorum description et usus. London: Flesher; 1664.
5 Neuburger M. Die historische Entwicklung der experimentellen Gehirn- und Rückenmarksphysiologie vor Flourens. Stuttgart: Enke; 1897.

6 Haller A. First lines of physiology. New York, NY: Johnson Reprint; 1786. Vol. 1. (Reprinted in 1966).

7 Kellie G. An account of the appearances observed in the dissection of two of three individuals presumed to have perished in the storm of the $3 \mathrm{rd}$, and whose bodies were discovered in the vicinity of Leith on the morning of the 4th, November 1821: with some reflections on the pathology of the brain. Trans Med Chir Soc Edin. 1824;1:82-169.
8 Monro A. Observations on the structure and functions of the nervous system: illustrated with tables. Edinburgh: Creech; 1783.

9 Macintyre I. A hotbed of medical innovation: George Kellie (1770-1829), his colleagues at Leith and the Monro-Kellie doctrine. J Med Biogr. 2014;22:93-100.

10 Voogd J, Koehler PJ. Historic notes on anatomic, physiologic, and clinical research on the cerebellum. Handb Clin Neurol. 2018; 154:3-26.

11 Greenblatt SH. A surgeon for the brain. Brain. 2007;130:303-6. 